\title{
Changes in pulmonary artery pressure in infants with respiratory distress syndrome following treatment with Exosurf
}

Liverpool Maternity Hospital, Oxford Street, Liverpool L7 7BN

A H Hamdan

N J Shaw

Correspondence to: Dr N J Shaw, Regional Neonatal Intensive Care Unit, Liverpool Maternity Hospital, Liverpool L7 7BN. Accepted 7 February 1995

A H Hamdan, N J Shaw

\begin{abstract}
The pulmonary artery pressure (PAP) changes were studied using Doppler echocardiography in preterm infants treated with an artificial surfactant (Exosurf) during the acute phase of respiratory distress syndrome (RDS). The ratio of pulmonary artery acceleration time to the right ventricular ejection time (AT:RVET), measured from the Doppler wave form, was determined in 38 infants before the first dose of Exosurf, at one and six hours after the first dose, immediately before the second dose of Exosurf, and at one, six, 12, 36, and 60 hours subsequently. The median AT:RVET ratio corrected for heart rate (AT:RVET(c)) increased significantly an hour after administration of the first dose of Exosurf from 0.330 $(0.273-0.410)$ to $0.380(0.303-0.445)$ and similarly an hour after the second dose from $0.426 \quad(0.252-0.495)$ to 0.440 $(0.373-0.500)$. These changes occurred against a steady increase in the median AT:RVET(c) over the first 72 hours.

It is concluded that the reduction in PAP correlates well with clinical parameters of disease severity and raises questions regarding the mode of action of Exosurf.

(Arch Dis Child 1995; 72: F176-F179)
\end{abstract}

Keywords: pulmonary artery pressure, respiratory distress syndrome, Exosurf.

Neonatal respiratory distress syndrome (RDS) is characterised by respiratory distress at, or shortly after, birth that increases in severity, reaching its peak within three days, after which there is gradual improvement. ${ }^{1}$ Recovery is often heralded by spontaneous diuresis and is indicated by the ability to oxygenate the infant with lower inspired oxygen concentrations.

A high pulmonary artery pressure (PAP) during the acute phase of RDS has been documented by both direct and indirect methods. ${ }^{23}$ Doppler echocardiography provides a noninvasive means by which to assess PAP. ${ }^{4}$ Studies of the ratio of pulmonary artery acceleration time (time to peak velocity of pulmonary blood flow) to the right ventricular ejection time (AT:RVET), measured from either a continuous or pulsed Doppler waveform, has a close inverse correlation with PAP. ${ }^{4-7}$ Results from studies of the AT:RVET ratio suggest that PAP falls by 30 hours in the term infant and by 60 hours in the uncomplicated preterm infant, ${ }^{8}$ although other work measuring the maximal tricuspid regurgitant jet velocity, when present, has suggested that pulmonary artery pressure falls at the same rate in term and preterm infants after birth. ${ }^{9}$ In infants with hyaline membrane disease PAP falls more slowly and rises again in some. ${ }^{10}$ The latter phenomenon may be an indicator of the subsequent development of bronchopulmonary dysplasia. ${ }^{11}$

In animal studies endotracheal administration of surfactant acutely decreases pulmonary vascular resistance, leading to a decrease in the PAP. ${ }^{12}$ Kääpä et al, using Doppler to determine the systolic PAP from the tricuspid valve regurgitant flow velocity after administration of Exosurf, have shown that this depressor effect is present at 15 minutes and is maintained for one hour after surfactant instillation. ${ }^{13}$ The decrease in PAP was, however, found to be temporary in this study, subsiding within 12 hours of treatment, ${ }^{14}$ although the same authors have also shown a persistent and continuing fall in PAP after surfactant treatment. ${ }^{15}$ To our knowledge Doppler studies have not been undertaken in RDS before, and after the first and the second dose of surfactant. The aim of this study was therefore to use Doppler echocardiography to study the natural history of the PAP in preterm infants who were treated with surfactant during the acute phase of RDS.

\section{Methods}

The study was carried out between 1 January 1994 and 30 April 1994. All infants admitted to the neonatal intensive care unit at Liverpool Maternity Hospital who received surfactant were eligible for study. Those who died within 24 hours of birth and those with congenital anomalies affecting cardiorespiratory function were excluded.

Synthetic surfactant (Exosurf, Wellcome) is administered as early as possible after birth to all intubated infants under 28 weeks of gestation and to those over 28 weeks of gestation who have a clinical or radiological diagnosis of RDS or whose arterial:alveolar oxygen ratio is less than $0 \cdot 22 .{ }^{16}$ The surfactant is administered via the endotracheal route using a sideport in the endotracheal connector, in two doses of $5 \mathrm{ml} / \mathrm{kg}$ over $15-30$ minutes, 12 hours apart.

Doppler ultrasound examinations were performed before and one, six, and 12 hours after the first and second doses of Exosurf. 
Table 1 Maximum PIP and maximum $\mathrm{FIO}_{2}$ received over first 72 hours in infants with $\operatorname{RDS}(n=38)$

\begin{tabular}{lllllll}
\hline $\begin{array}{l}\text { Time } \\
\text { interval } \\
\text { in hours }\end{array}$ & $\begin{array}{l}\text { Maximum } \\
\text { PIP } \\
\text { (median) }\end{array}$ & Range & $\begin{array}{l}\text { Interquartile } \\
\text { range }\end{array}$ & $\begin{array}{l}\text { Maximum } \\
\text { IIO }_{2} \\
\text { (median) }\end{array}$ & Range & $\begin{array}{l}\text { Interquartile } \\
\text { range }\end{array}$ \\
\hline $0-4$ & 20 & $10-30$ & $18-22$ & $0 \cdot 73$ & $0 \cdot 29-1$ & $0 \cdot 57-0 \cdot 97$ \\
$5-8$ & 18 & $10-30$ & $15-21$ & $0 \cdot 53$ & $0 \cdot 25-1$ & $0 \cdot 42-0 \cdot 81$ \\
$9-12$ & $16 \cdot 5$ & $11-30$ & $14-21$ & $0 \cdot 57$ & $0 \cdot 21-1$ & $0 \cdot 34-0 \cdot 85$ \\
$13-16$ & $15 \cdot 5$ & $0-35$ & $13-20$ & $0 \cdot 50$ & $0 \cdot 21-0 \cdot 99$ & $0 \cdot 35-0 \cdot 72$ \\
$17-20$ & 16 & $0-35$ & $12-18$ & $0 \cdot 53$ & $0 \cdot 21-1$ & $0 \cdot 36-0 \cdot 71$ \\
$21-24$ & 16 & $0-27$ & $13-19$ & $0 \cdot 50$ & $0 \cdot 21-1$ & $0 \cdot 33-0 \cdot 65$ \\
$25-48$ & 16 & $0-30$ & $13-22$ & $0 \cdot 51$ & $0 \cdot 21-1$ & $0 \cdot 36-0 \cdot 81$ \\
$49-72$ & 15 & $0-26$ & $0-20$ & $0 \cdot 45$ & $0 \cdot 21-1$ & $0 \cdot 28-0 \cdot 64$ \\
\hline
\end{tabular}

Examinations were performed by a single observer $(\mathrm{AHH})$. All infants were studied using an ATL ultramark 4 scanner with a $5 \mathrm{MHz}$ range, gated, pulsed wave Doppler probe. Two dimensional imaging was performed with a $7.5 \mathrm{MHz}$ probe. The pulmonary artery was visualised from the parasternal long axis view by rotating the probe and angling upwards until the right ventricular outflow tract, pulmonary valve, and main pulmonary artery were visualised. The sample volume of the range gated Doppler signal was placed distal to the pulmonary valve and the Doppler signal recorded. A sweep speed of $100 \mathrm{~mm} / \mathrm{second}$ made it possible to identify individual Doppler waveforms. A minimum of five waveforms were recorded onto the system's computer module for off-line analysis. AT was measured from the onset of ejection to peak velocity; RVET was measured from the onset to the cessation of ejection. The AT:RVET ratio was corrected for heart rate by dividing by the square root of the $R-R$ interval. ${ }^{17} \mathrm{~A}$ satisfactory Doppler signal had to be obtained for the child to be included in the study. Data were analysed if infants were stable before and during Doppler studies and had no rapid swings of transcutaneous carbon dioxide or oxygen saturation, $\mathrm{pH}$, or blood pressure while being studied.

Ductal patency was not assessed during the procedure and right ventricular function was assessed subjectively at each echocardiographic study.

The maximum fractional inspired oxygen concentration $\left(\mathrm{FIO}_{2}\right)$ and peak inspiratory pressure (PIP) during each four hour period from birth, for the first 24 hours, and subsequently every 24 hours until 72 hours of age, were recorded.

The overall average rate of increase of AT:RVET was estimated from Doppler recordings taken at one and 12 hours after the first and second doses of Exosurf. One hour's worth of this was subtracted from the observed

Table 2 Pulmonary artery, Doppler results in infants treated with Exosurf

\begin{tabular}{|c|c|c|c|c|}
\hline $\begin{array}{l}\text { Time after first dose of Exosurf } \\
\text { of Doppler examination }\end{array}$ & $\begin{array}{l}\text { No of } \\
\text { infants } \\
\text { studied }\end{array}$ & $\begin{array}{l}A T: R V E T(c) \\
\text { (median) }\end{array}$ & Range & $\begin{array}{l}\text { Interquartile } \\
\text { range }\end{array}$ \\
\hline $\begin{array}{l}0 \text { (before first dose) } \\
1 \\
6 \\
12 \text { (before second dose) } \\
13 \text { (one hour after second dose) } \\
18 \\
24 \\
48 \\
72\end{array}$ & $\begin{array}{l}19 \\
19 \\
26 \\
32 \\
30 \\
32 \\
33 \\
34 \\
32\end{array}$ & $\begin{array}{l}0.330 \\
0.380 \\
0.404 \\
0.426 \\
0.440 \\
0.457 \\
0.473 \\
0.489 \\
0.510\end{array}$ & $\begin{array}{l}0 \cdot 273-0.410 \\
0 \cdot 303-0.445 \\
0 \cdot 273-0.465 \\
0 \cdot 252-0.495 \\
0.373-0.500 \\
0.374-0.510 \\
0.397-0.526 \\
0.421-0.550 \\
0.423-0.557\end{array}$ & $\begin{array}{l}0 \cdot 306-0.369 \\
0 \cdot 357-0 \cdot 412 \\
0 \cdot 369-0 \cdot 421 \\
0 \cdot 386-0 \cdot 449 \\
0 \cdot 410-0 \cdot 468 \\
0 \cdot 426-0 \cdot 476 \\
0 \cdot 457-0 \cdot 502 \\
0 \cdot 469-0.513 \\
0 \cdot 480-0 \cdot 540\end{array}$ \\
\hline
\end{tabular}

increases from before and one hour after Exosurf was given, and the results were compared with zero using the paired Wilcoxon test. Pearson's correlation coefficient was calculated for the relation between the fall in $\mathrm{FIO}_{2}$ and PIP rise in AT:RVET.

\section{Results}

Forty six infants were eligible for study. Seven died within 24 hours of birth and one was excluded because of congenital malformation and hydrops. The median gestational age of the remaining 38 infants included in the study was 28 weeks (range 23-38 weeks) and the median birthweight was $1008 \mathrm{~g}$ (range $580-4300 \mathrm{~g}$ ). Five of these infants subsequently died. The maximum PIP and maximum $\mathrm{FIO}_{2}$ received for each four hour interval over the first 24 hours and thereafter each 24 hours for the first $\mathbf{7 2}$ hours are shown in table 1. The maximum $\mathrm{FiO}_{2}$ received dropped significantly between the first and second four hour periods after birth $(\mathrm{p}<0 \cdot 05)$. The maximum PIP received also fell significantly between the first and second four hour periods after birth $(p<0.05)$.

The results of the pulmonary artery Doppler studies, together with the number of infants studied each time, are shown in table 2 . Results for some infants had to be excluded each time that Doppler examination was carried out, owing to the instability of some of the babies being studied. There was a steady increase in the median AT:RVET(c) ratio over the first 24 hours (figure). The median corrected AT:RVET ratio (AT:RVET(c)) increase was significantly higher in the hour after administration of the first dose of surfactant $(0.330$ (range $0.273-0.410$ ) to 0.380 (range $0.303-0.445)$ ) when compared with the time from one to 12 hours after the first dose had been given $(0.380$ (range $0.303-0.445)$ to 0.426 (range $0.252-0.495$ ); $\mathrm{p}<0.0001$ ). A similar significantly higher increase in AT:RVET(c) was found in the hour after administration of the second dose of surfactant $(0.426$ (range $0.252-0.495$ ) to 0.440 (range $0.373-0.5)$ when compared with the subsequent 11 hour period $(0.44$ (range $0.373-0.5)$ to 0.473 (range $0.397-0.526) ; \mathrm{p}<0.0001$ ). Right ventricular function was regarded as normal in all infants throughout the study.

The change in AT:RVET(c) ratio over the first 72 hours correlated significantly with the fall in $\mathrm{FIO}_{2}(\mathrm{R}=0.97 ; \mathrm{p}<0.001)$ and the fall in peak inspiratory pressure $(R=0.93 ; p<0.01)$.

\section{Discussion}

An indirect measurement of pulmonary artery pressure shows that administration of two doses of synthetic surfactant is associated with a significant fall in PAP an hour after each dose, and that these acute reductions are against a background of a gradual and persistent fall. The indirect method we used to measure PAP has been described before. ${ }^{3411}$ A close correlation has been shown between the AT:RVET ratio and directly measured 


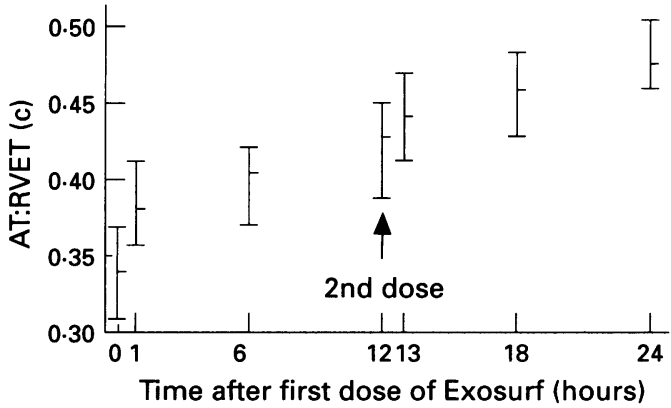

Changes in AT:RVET(c) with time in infants with RDS treated with Exosurf (median and interquartile range).

PAP in older infants and children. ${ }^{67}$ Although the AT:RVET ratio correlates with PAP, it can be influenced by myocardial contractility and heart rate. ${ }^{17}$ All our measurements were made by one observer who subjectively assessed right ventricular function during each Doppler study, as previous workers have, ${ }^{11}$ and judged it to be normal in all infants.

Kääpä et al, using echocardiographic assessment of the tricuspid regurgitant jet when detected, reported a reduction in PAP within 15 minutes after instillation of Exosurf. ${ }^{13}$ This effect was maintained for an hour but appeared to be transient, subsiding within 12 hours of surfactant administration. ${ }^{15}$ In contrast, we found that a persistent and sustained fall in PAP occurs after Exosurf instillation. The major disadvantage of estimating PAP from the tricuspid regurgitant jet flow velocity is that tricuspid regurgitation may not always be measurable. Previous studies have reported measurable tricuspid regurgitation in between $31 \%-92 \%$ of Doppler studies of preterm infants. $^{9} 1418$ The difference between the results of our study and some of those of Kääpä et al could be explained by postulating that infants in whom tricuspid regurgitation is measurable have the most severe pulmonary hypertension, which may be associated with only a transient fall in PAP whereas, as a whole, in preterm infants the fall is sustained.

Studies of term infants using Doppler measuring AT:RVET have shown that PAP falls to within the normal range by 24 hours whereas in preterm infants who do not have RDS this is not achieved until 72 hours. ${ }^{8}$ Other studies of AT:RVET performed in the presurfactant era on preterm infants during the acute phase of RDS have shown that PAP falls within the first 40 hours, tending to remain static for the next few days. ${ }^{3}$ In contrast, we found a more rapid and steady decrease in PAP over the first three days in the acute phase of RDS, an effect likely to be caused by surfactant treatment.

Stenson et al have recently reported changes that occur in static respiratory compliance in preterm infants, following administration of synthetic surfactant (Exosurf) and natural surfactant (Curosurf), and have compared their effects. ${ }^{19}$ These workers showed that respiratory compliance had increased three hours after the administration of Curosurf and had increased further by 12 hours. In contrast, the administration of Exosurf was not associated with any change in respiratory compliance over the first 12 hours. However, this and other studies, including our own, have reported a reduction in $\mathrm{FIO}_{2}$ and PIP being used three and 12 hours after administration of Exosurf. ${ }^{19-21}$ This, together with the significant fall in PAP that we have demonstrated an hour after administration of Exosurf, suggest a possible acute clinical effect. We suggest that Exosurf may have an early effect in the course of RDS. Given that lung function does not seem to improve in the first 12 hours, we speculate the Exosurf may act during this period principally as a pulmonary vasodilator thereby improving pulmonary blood flow and resulting in a reduced oxygen and ventilatory requirement. The contribution of the non-phospholipid components of Exosurf (tyloxapol and hexadecanol) to this possible effect is open to debate. Following the very early phase of RDS (the first 12 hours) Exosurf may then exert its primary surfactant effect on the lungs and improve pulmonary compliance, although this has, to our knowledge, yet to be confirmed.

In conclusion, we have for the first time shown dramatic acute changes in PAP associated with administration of a synthetic surfactant (Exosurf) to infants with RDS. These changes, which correlate well with clinical parameters of disease severity, raise questions regarding the mode of action of synthetic surfactants.

1 Morley CJ. The respiratory distress syndrome. In: Roberton NRC, ed. Textbook of neonatology. Edinburgh: Churchill Livingstone, 1986: 274-311.

2 Moss AJ, Emmanoulidides GC, Petteri O, Higashino SM, Adams FH. Postnatal circulatory and metabolic adjustments in normal and distressed premature infants. Biol Neonate 1965; 8: 177-97.

3 Evans NJ, Archer LNJ. Doppler assessment of pulmonary artery pressure and extra pulmonary shunting in the acute phase of hyaline membrane disease. Arch Dis Child 1991; 66: 6-11

4 Kitabatake A, Inoue M, Asao M, Masuyama T, Tanouchi J, Morita $\mathrm{T}$, et al. Noninvasive evaluation of pulmonary hypertension by a pulsed Doppler technique. Circulation 1983; 68: 302-9.

5 Martin-Duran R, Larman M, Trugeda A, Vazquez de Prada JA, Ruano J, Torres A, et al. Comparison of Dopplerdetermined elevated pulmonary artery pressure with pressure measured at cardiac catheterisation. Am $\mathcal{f}$ Cardiol pressure measured

6 Kosturakis D, Goldberg SJ, Allen HD, Loeber C. Doppler echocardiographic prediction of pulmonary arterial hypertension in congenital heart disease. Am f Cardiol 1984; 53: $1110-5$

7 Akibe T, Yoshikawa M, Otaki S, Kobayashi Y, Nakasato M, Suzuki $\mathrm{H}$. Prediction of pulmonary artery pressure by continuous-wave Doppler echocardiography in infants and children. Pediatr Cardiol 1988; 9: 225-9.

8 Evans NJ, Archer LNJ. Postnatal circulatory adaptation in healthy term and preterm neonates. Arch Dis Child 1990 65: 24-6.

9 Skinner JR, Boys RJ, Hunter S, Hey EN. Non-invasive assessment of pulmonary arterial pressure in healthy neonates. Arch Dis Child 1991; 66: 386-90.

10 Evans NJ, Archer LNJ. Doppler assessment of pulmonary artery pressure during recovery from hyaline membrane

11 Gill AB, Weindling AM. Pulmonary artery pressure changes in the very low birthweight infant developing chronic lung disease. Arch Dis Child 1993; 68: 303-7.

12 Clyman RI, Jobe A, Heymann M, Ikegami M, Roman C, Payne B, et al. Increased shunt through the patent ductus arteriosus after surfactant replacement therapy. Pediatrics 1982; 100: 101-7.

13 Kääpä P, Seppänen $M$, Kero $P$, Saraste $M$. Pulmonary hemodynamics after synthetic surfactant replacement in neonatal respiratory distress syndrome. $\mathcal{F}$ Pediatr 1993; 123: 115-9.

14 Kääpä $P$, Kero $P$, Saraste $M$. Synthetic surfactant replacement therapy decreases estimated pulmonary artery pres-
sure in respiratory distress syndrome. $\mathrm{Am} \mathcal{f}$ Dis Child 1992; 146: 961-4.

15 Seppänen MP, Kääpä PO, Kero PO, Saraste M. Dopplerderived pulmonary artery pressure in acute neonatal respiratory distress syndrome. Pediatrics 1994; 93: 769-73. 
16 The Osiris Collaborative Group. Early versus delayed neonatal administration of a synthetic surfactant - the judgment of OSIRIS. Lancet 1992; ii: 1363-9.

17 Serwer GA, Cougle AG, Eckerd JM, Armstrong BE Factors affecting use of the Doppler-determined time from flow onset to maximal pulmopary artery velocity for velocity for measurement of pulmonary artery pressure in children. Am f Cardiol 1986; 58: 352-6.

Skinner JR, Boys RJ, Hunter S, Hey EN. Pulmonary and systemic arterial pressure in hyaline membrane disease

19 Stench Dis Child 1992; 67: 366-73.

Stenson BJ, Glover RM, Parry GJ, Wilkie RA, Laing IA, Tarnow-Mordi WO. Static respiratory compliance in the newborn. III: Early changes after exogenous surfactant treatment. Arch Dis Child 1994; 70: F19-F24.

20 Long W, Corbet A, Cotton R, Courtney S, The American Exosurf Neonatal Study Group I, The Canadian Exosurf Neonatal Study Group, et al. A controlled trial of synthetic surfactant in infants weighing $1250 \mathrm{~g}$ or more with respiratory distress syndrome. $N$ Engl f Med 1991; 325: $1696-703$.

Long W, Thompson T, Sundell H, Schumacher R, Volberg $F$, Guthrie R. Effects of two rescue doses of synthetic surfactant on mortality in 700-to-1350 gram infants with respiratory distress syndrome. $\mathcal{f}$ Pediatr 1991; 118: 595-605. 